\title{
LABORATORY STUDY OF RUBBLE FOUNDATIONS FOR VERTICAL BREAKWATERS
}

\author{
A. Brebner \\ Chairman, Department of Civil Engineer ing \\ Queen's University at Kingston, Ontar10 \\ and \\ P. Donnelly \\ Engineer, Harbour and Rivers Branch \\ Department of Public Works, Canada
}

\begin{abstract}
Laboratory tests have been conducted to determine the stability characteristics of pell-mell placed rubble of sensibly uniform shape and size used as a foundation or as toe protection for the vertical super structure of a composite breakwater. Data are presented for the design of such breakwater foundations.
\end{abstract}

\section{INTRODUCTION}

An investigation is being conducted in the Hydraulic Laboratories at Queen's University at Kingston, on the behaviour under wave attack of the rubble portion of a composite breakwater consisting of a vertical breakwater atop a rubble-mound.

This study is part of a general program on harbour problems on the Great Lakes of Canada and is a preliminary effort to provide a rational basis for the design of such rubble sections to withstand the erosive action of waves.

The forces exerted by wind-generated waves on breakwaters and allied structures have, for many years, being the subject of theoretical, laboratory and field study. Most of this effort has been directed towards evaluating the effects of waves on rubble-mound breakwaters, Iribarren (1951), Beaudevin (1955) and Hudson (1959), and the forces exerted on the face-walls of vertical breakwaters, Minikin (1950) and Nagaı (1960).

Apparently no systematic study of the well recognized problem of erosion of the foundations (usually rubble-mound) of composite breakwaters has been made.

Figure I illustrates the three main types of breakwater, I(c) being the type under investigation. This latter type might well be selected instead of the purely vertical structure for the following cases:

a) where the seambed has insufficient strength to bear the concentrated loads associated with vertical gravity walls; 


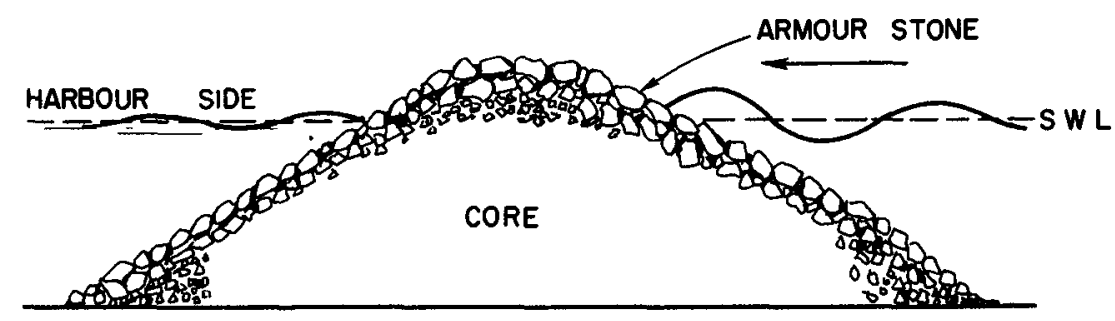

(a) TYPICAL RUBBLE MOUND BREAKWATER

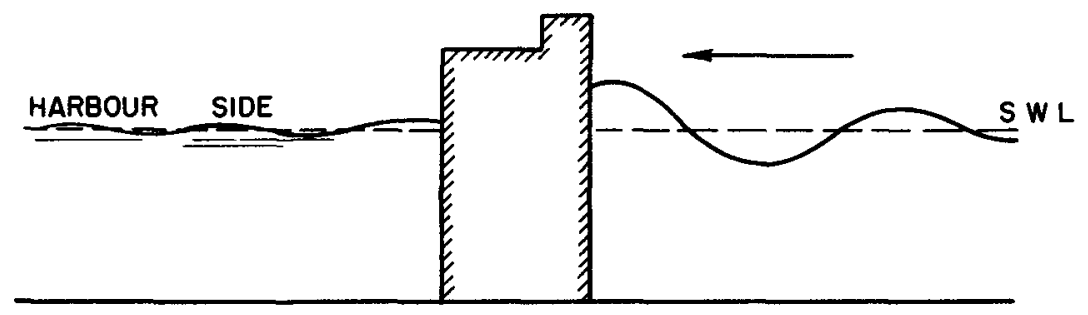

(b) TYPICAL VERTICAL WALL BREAKWATER

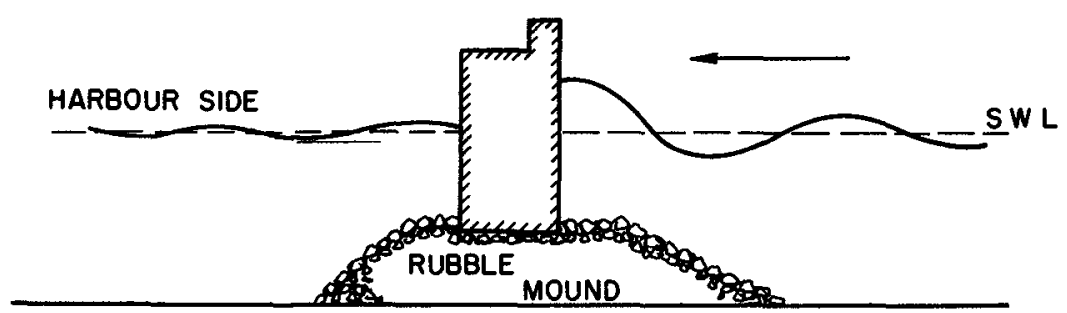

(c) TYPICAL COMPOSITE BREAKWATER

Fig. 1. Breakwater cross-sections.

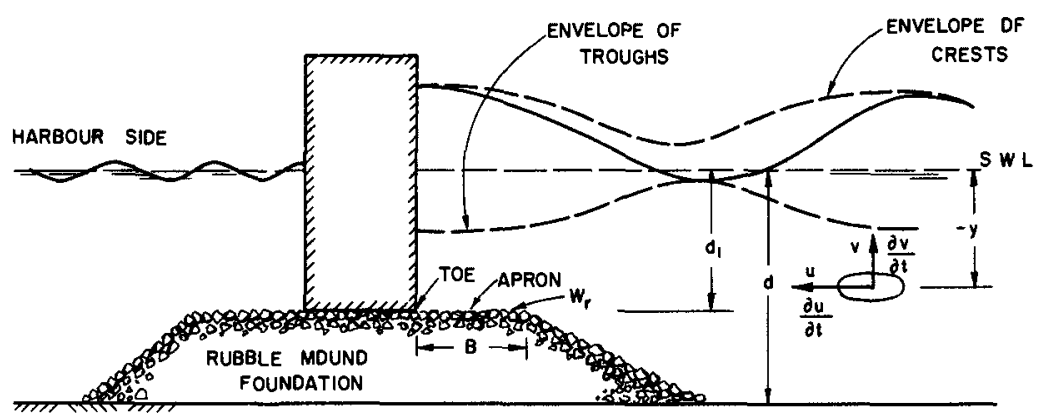

Fig. 2. Composite breakwater under wave attack (Definitions of nomenclature). 


\section{COASTAL ENGINEERING}

b) where scour of the bed material is a problem;

c) where great depths make it uneconomical to build a rubblemound breakwater - a $33 \%$ increase in height requires a $50 \%$ increase in volume of stone for the same side-slopes and top width of rubble-mound.

From a practical viewpoint the design of the superstructure of the composite breakwater may follow established procedures, B.E.B. (196I), whereas the necessary size and weight of stone for the foundation portion is, at present, a matter of engineering judgement.

In what follows an attempt is made to make the selection of stone size a rational one based on extrapolated laboratory tests.

\section{STABILITY ANALYSIS}

The forces on an individual unit of a rubble mound foundation of a vertical wall situated at a depth $d_{1}$ below the S.W.L. will be considered. The conditions are illustrated in Figure 2. The disturbing force is taken to consist of inertia and drag components. The inertia force on a body submerged in an oscillating fluid is proportional to the product of the volume of the body, the mass of the fluid and the local acceleration of the fluid; thus

$$
\text { Inertia Force }=F_{I}=C_{M} D^{3}\left(\gamma_{f} / g\right) \frac{\partial v}{\partial t}
$$

where $C_{M}$ is an inertia coefficient. (Notation is defined in the appendix.)

The drag force on a body in an os cillating fluid is proportional to the product of the cross-sectional area of the body, the mass of the fluid, and the square of the velocity of the oscillating fluid; thus

$$
\text { Drag Force }=F_{D}=\frac{1}{2} C_{D} D^{2}\left(\gamma_{f} / g\right) v|v|
$$

where $C_{D}$ is a drag coefficient.

In the case of the rubble unit of the foundation under study, the velocities and accelerations in the vicinity of the rubble unit are not known since the presence of the mound modified the orbital velocities and accelerations which would exist in the clapotis arising from a vertical wall with no mound in front of it. However, it will be assumed that the velocities and accelerations actually existing around the rubble units are directly proportional to those which would exist at the corresponding depth in a total clapotis. A rubble unit will be subjected to disturbing forces with horizontal and vertical components. The restoring force will be the buoyant weight. Considering incipient horizontal dis placement of the unit, the condition of limitıng equilibrium is:

$$
\sum F_{H}=\mu \sum F_{V}
$$




\section{LABORATORY STUDY OF RUBBLE FOUNDATIONS \\ FOR VERTICAL BREAKWATERS}

where $\sum F_{H}=$ sum of horizontal forces

$\sum F_{V}=$ sum of vertical forces

$\mu=$ friction coefficient

$\sum F_{H}=$ Horizontal Inertia Force + Horizontal Drag Force

$$
=F_{H I}+F_{H D}
$$

$\sum F_{V}=\underset{\text { Buoyant } W \text { eight }+\mid \text { Vertical Inertia Force }|+| \text { Vertical }}{\text { Drag Forcel }}$

= Buoyant Weight $+F_{V I}+F_{V D}$

According to first order gravity wave theory, the horizontal and-vertical components of orbital velocity and acceleration, in a total clapotis at a depth $d_{1}$ below the S.W.L. where the water depth is d, are:

$$
U=H k \frac{\cosh m d\left(1-d_{1} / d\right)}{\sinh m d} \sin m x \sin k t
$$

$=U_{\max } \sin k t$

where $U_{\max }$ denotes the maximum horizontal component of orbital velocity at a point. Simllarly,

$$
\begin{aligned}
v & =-H k \frac{\sinh m d\left(1-d_{1} / d\right)}{\sinh m d} \cos m x \sin k t \\
& =-v_{\max } \sin k t
\end{aligned}
$$

$$
\begin{aligned}
\frac{\partial u}{\partial \dagger} & =H k^{2} \frac{\cosh m d\left(1-d_{1} / d\right)}{\sinh m d} \sin m x \cos k \uparrow \\
& =\left[\frac{\partial u}{\partial \dagger}\right]_{\max } \cos k t
\end{aligned}
$$

$$
\begin{aligned}
\frac{\partial v}{\partial t} & =-H k^{2} \frac{\sinh m d\left(1-d_{1} / d\right)}{\sinh m d} \sin m x \cos k t \\
& =-\left[\frac{\partial v}{\partial t}\right]_{\max } \cos k t
\end{aligned}
$$




\section{COASTAL ENGINEERING}

Recalling equations (1) and (2), the horizontal and vertical force components are written:

Horizontal Inertia Force $\left(F_{\mathrm{HZ}}\right)$

$$
F_{H 1}=C_{M H} D^{3}\left(f_{f} / g\right)\left[\frac{\partial u}{\partial t}\right]_{\max } \cos k t
$$

Horizontal Drag Force $\left(F_{H D}\right)$

$$
F_{H D}=\frac{1}{2} C_{D H} D^{2}\left(\gamma_{f} / g\right) u_{\max }^{2} \sin k t|\sin k t|
$$

Vertical Inertia Force $\left(F_{V I}\right)$

$$
F_{V I}=-C_{M V} D^{3}\left(\gamma_{f} / g\right)\left[\frac{\partial v}{\partial t}\right]_{\max } \cos k t
$$

Vertical Drag Force $\left(F_{\text {VD }}\right)$

$$
F_{V D}=\frac{1}{2} C_{D V} D^{2}\left(\gamma_{f} / g\right) \cdot v_{\text {max }}^{2} \sin k t|\sin k t|
$$

The coefficients $C_{M H}, C_{D H}, C_{M V}$, and $C_{D V}$ are the appropriate horizontal and vertical inertia and drag coefficients whose values take care of the discrepancy between actual and as sumed velocities and accelerations.

$$
\text { Buoyant Weight }=\beta D^{3}\left(\gamma_{r}-\gamma_{f}\right)
$$

where the coefficient $\beta$ depends on the shape of the unit.

It is evident that the maximum values of the above periodic forces do not occur at the same time. However, movement of the stone in question is initiated by action of vertical wave forces, which reduce thi effective buoyant weight of the stone, simultaneous with, or closely followed by, a horizontal wave force which tends to displace the "lightened" stone. It will further be as sumed that the "lightenin ${ }^{\prime \prime}$ action is effected by the combined efforts of the maximum vertical inertia and drag forces, and that the disturbing force is given by the combined efforts of the maximum horizontal inertia and drag forces. Since here we are dealing with proportionalities rather than real, actual forces, this simplification is justified. Therefore, dropping the periodic terms of equation (6) which define the magnitude and direction of each component force at the particular point, the equation of limiting equilibrium is written: 


$$
\begin{aligned}
& C_{M H} D^{3}\left(\gamma_{f} / g\right)\left[\frac{\partial u}{\partial t}\right]_{\max }+\frac{1}{2} C_{D H} D^{2}\left(\gamma_{f} / g\right) \cdot u_{\max }^{2} \\
& \quad=\mu\left\{\beta D^{3}\left(\gamma_{f}-\gamma_{f}\right)-C_{M V} D^{3}\left(\gamma_{f} / g\right)\left[\frac{\partial v}{\partial f}\right]_{\max }-\frac{1}{2} C_{D V} D^{2}\left(f_{f} / g\right) \cdot v_{\max }^{2}\right\}
\end{aligned}
$$

Since the weight of the rubble untt $=w_{r}=\beta D^{3} \gamma_{r} \quad$ we have

$$
\frac{W_{r}}{\gamma_{r}}=\frac{\beta}{8}\left[\frac{C_{D H} u_{\max }^{2}+C_{D V} v_{\max }^{2}}{\mu \beta g\left(S_{r}-1\right)-\left\{C_{M H}\left[\frac{\partial u}{\partial t}\right]_{\max }+\mu C_{M V}\left[\frac{\partial v}{\partial t}\right]_{\max }\right\}}\right]^{3}
$$

where $s_{r}=\frac{\gamma_{r}}{\gamma_{f}}$

Now recalling from equation (5) the values of $u_{\max }, v_{\max }$, $\left[\frac{\partial u}{\partial t}\right]_{\max }$ and $\left[\frac{\partial v}{\partial t}\right]_{\max }$, substituting these values in the above equation, and then multiplying both sides of the resulting equation by $\left[\frac{S_{r}-1}{H}\right]^{3}$
gives:

$$
\frac{W_{r}\left(S_{r}-1\right)^{3}}{H^{3} \gamma_{r}}=\frac{\beta}{8}\left[\frac{C_{D H} \frac{\cosh ^{2} m d\left(1-d_{1} / d\right)}{\sinh ^{2} m d}+C_{D V} \frac{\sinh ^{2} m d\left(1-d_{1} / d\right)}{\sinh ^{2} m d}}{\frac{\mu \beta g}{H k^{2}}-\frac{1}{S_{r}-1}\left\{C_{M H} \frac{\cosh m d\left(1-d_{1} / d\right)}{\sinh m d}+\mu C_{M V} \frac{\sinh m d\left(1-d_{1} / d\right)}{\sinh m d}\right\}}\right.
$$
recall that:

$$
\text { Now, if we put } C_{D V}=\sigma_{1} C_{D H}, C_{M V}=\sigma_{2} C_{M H} \text { and } \mu=1 \text {, }
$$

$$
\begin{aligned}
& k=2 \pi / T \\
& L=\left(g T^{2} / 2 \pi\right) \text { tanh } m d
\end{aligned}
$$

and adopt the notation of Hudson (1959) by writing the above equation in terms of the Stability Number, $N_{s}$, such that

the result is:

$$
N_{S}=\frac{\gamma_{r}^{1 / 3} H}{w_{r}^{1 / 3}\left(s_{r}-1\right)}
$$


COASTAL ENGINEERING
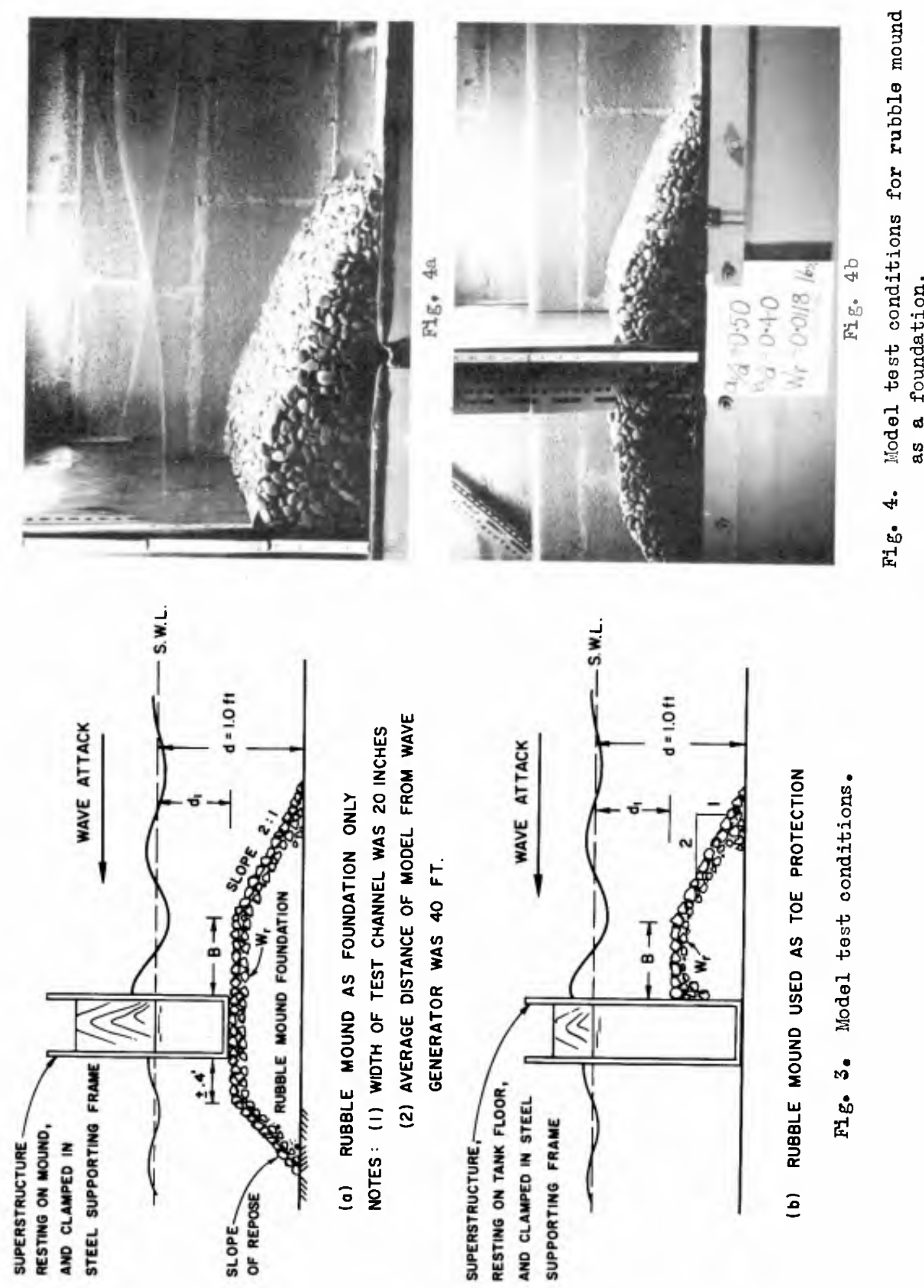


\section{LABORATORY STUDY OF RUBBLE FOUNDATIONS FOR VERTICAL BREAKWATERS}

$N_{s}=\frac{2}{\beta^{1 / 3}} \frac{\left[\frac{\beta}{2 \pi \tanh m d} \cdot \frac{1}{C_{M H}} \cdot \frac{L}{H}\right]-\frac{1}{S_{r}-1} \cdot \frac{\cosh m d\left(1-d_{1} / d\right)}{\sinh m d}\left\{1+\sigma_{2} \tanh m d\left(1-d_{1} / d\right)\right\}}{\frac{C_{D H}}{C_{M H}} \cdot \frac{\cosh ^{2} m d\left(1-d_{1} / d\right)}{\sinh ^{2} m d}\left\{1+\sigma_{1} \tanh ^{2} m d\left(1-d_{1} / d\right)\right\}}$ $7(0)$

Although equation $7(a)$ is based on very simplified assumptions and contains a number of unkown coefficients, it does serve the useful purpose of identifying the principal parameters involved in the problem. These may be lis ted as follows:

1) the term $\beta, 1 . e$. related to the shape of the rubble units, $\Delta$,

2) the term $C_{D H} / C_{M H}$, 1.e. elated to the ratio of inertia and drag coefficients, $C_{D} / C_{M}$.

3) the term $\frac{1}{C_{M H}} \frac{L}{H}, i_{0}$ e. related to the product of wave steepness and inertia coefficient, $C_{M} H / L$.

4) the specific gravity of the rubble units, $S_{r}$.

5) the term $m d, 1 . e$ related to the relative depth, d/L。

6) the relative depth of the foundation with reference to the S.W.L., $d_{1} / d$.

Therefore the Stability Number may be written:

$$
N_{s}=f\left(\Delta, C_{D} / C_{M}, C_{M} H / L, S_{r}, d / L \text {, and } d_{1} / d\right) \quad 7(b
$$

where $f$ reads "a function of".

\section{EXPERIMENTAL WORK}

A series of experiments was carried out to investigate the influence of the various parameters as noted in equation (7) on the Stability Number.

Figure 3 illustrates the experimental conditions and Figure 4 shows photo fraphs of the installation under test.

Range of Test Conditions:- The following tabulation gives the ranges of wave characteristics and breakwater dimensions used in the tests: 


\section{COASTAL ENGINEERING}

Characteristics and Dimensions

Water depth (d)

Wave height $(H)$

Wave period ( $T$ )

Wave length ( $L$ )

Relative depth ( $d / L)$

Wave steepness ( $H_{\text {crit }} / L$ )(at limiting equilibrium)

Specific weight of stone $\left(\gamma_{r}\right)$

Average weight of individual rubble units

Specific weight of water $\left(\gamma_{f}\right)$

$$
\left(W_{r}\right)
$$

Relative depth of top surface of foundation mound below S.W.L. $\left(d_{1} / d\right)$

Top width of foundation mound on s eaward side (B)

(Note: Main body of tests conducted at

$$
B=0.4 \mathrm{~d} \text { ) }
$$

Slope of foundation mound on seaward side Crown elevation of vertical superstructure Test sections
Range of Test Conditions

$1.00 \mathrm{ft}$.

0.04 to $.445 \mathrm{ft}$.

1.00 to $2.00 \mathrm{secs}$.

4.51 to $10.76 \mathrm{ft}$.

0.0930 to 0.2215

.0074 to .0576

$165.4 \mathrm{lbs} . / \mathrm{cu} . \mathrm{ft}$.

0.00183 to $0.0190 \mathrm{lbs}$.

$62.4 \mathrm{lbs} . / \mathrm{cu} . \mathrm{ft}$.

0.00 to 0.75

$0.15 d$ to $0.75 d$

1 on 2

No overtopping

See Fi gure 3

Most of the tests were conducted with a top width of the foundation mound on the seaward side, $B$, of four-tenths the water depth (i.e. $B=0.4 \mathrm{~d}$ ), and zero penetration of the vertical super structure into the rubble mound foundation. Additional tests, in which the top width, $B$, and the penetration of the superstructure into the foundation mound were varied, are discussed in the section headed SUPPLEMENTARY TESTS.

In the experiments, the shape, $\Delta$, of the rubble units was kept sensibly constant, sub-rounded to sub-angular beach gravel of specific gravity 2.65 being used throughout. Four different stone sizes were used to correlate the parameters, $3 / 4 " 1-5 / 8 ", 5 / 8 "-1 / 2 "$, $1 / 2 "-3 / 8 ", 3 / 8 "-1 / 4 "$. The grading curves within each size range showed that the distribution of sizes was very similar in all cases; that 1s, similitude of size variation was being closely followed.

Since neither the drag nor the inertia coefficient of the stone was determined experimentally the data of Keulegan and Carpenter (1958) was used to provide an indication of the likely variations in the magnitude of these coefficients in the range of laboratory conditions encountered. These data indicated that the variation in numerical value was small over a wide range of wave steepnesses and stone sizes.

Thus the effective functional equation guiding the experimental work was reduced to the form 


\section{LABORATORY STUDY OF RUBBLE FOUNDATIONS FOR VERTICAL BREAKWATERS}

$$
N_{s}=\frac{\gamma_{r}^{1 / 3} H}{w^{1 / 3}\left(S_{r}-1\right)}=f\left(d / L, d_{1} / d \text {, and } H / L\right)
$$

and each of these dimensionless terms was investigated as outlined in the following.

For given fixed values of $d_{1} / d$ and $T, 1 . e$ a fixed value of wavelength, a foundation of one size of stone was tested with increasing values of wave-height, $H$. At small values of $H$ no movement of the stone was discernable whereas at high values of $H$ the rubble either rocked violently or was washed out from under the superstructure. It was consistently found that a relationship of the form shown in Figure 5 existed between $H$ and the number of stones rocking at the base of the vertical superstructure. The point of critical stability normally occurred when about four pieces per lineal foot were rocking; but, as might be expected, this critical condition was not always exactly definable. However by plottıng the test results as definitely stable (sensibly no movement) or unstable (wash out of at least two pieces) it was possible, as is seen in a typical test result, Figure 6 , to arrive at a reasonably accurate relationship between stone size and wave height at the point of limiting equilibrium between stable and unstable conditions.

Using the curve defining the conditions of limiting equilibrium for a given stone weight (under the fixed values of $d_{1} / d$ and $L$ ) the ratio $\frac{\gamma_{r}^{1 / 3} H_{c r i t}}{W_{r}^{1 / 3}\left(S_{r}-1\right)}$, that is the critical stability number, $N_{s}^{\prime}$ was calculated and plotted against the wave steepness $\frac{H_{c r i f}}{L}$. Such a plot is shown on Figure 7 and gives evidence of little effect of $\frac{H_{c r i f}}{L}$ on $N_{s}^{\prime}$.

From the whole series of tests treated in this manner with varying values of $d_{1} / d$ and varying values of $T$ (and hence $L$ and $d / L$ ) it was found that the critical stability number $N_{s}^{\prime}$ could, as a first approximation, be regarded as independent of the wave steepness

$H_{\text {crit }} / L$. In view of this, the mean value of $N_{s}^{\prime}$ as determined from the tests on the four sizes of stone was calculated and this mean value used to determine subsequent relationship between $N_{s}$ and $d / L$ or $d_{1} / d$.

Figure 8 shows the varration of the critical stability number with $d / L$ using $d_{1} / d$ as a parameter.

Again it appears from Figure 8 that relative depth $d / L$ is of secondary importance except where the depth of the foundation below S.W.L. is great. However, since it is possible to achieve a range of values of $d / L$ in a wave system in nature, the value of $N_{s}^{\prime}$ for the worst case of $d / L$ (i.e. the lowest point on each $N_{s}^{\prime}$ versus $d / L$ curve) is selected and plotted against $d_{l} / d$. 


\section{COASTAL ENGINEERING}

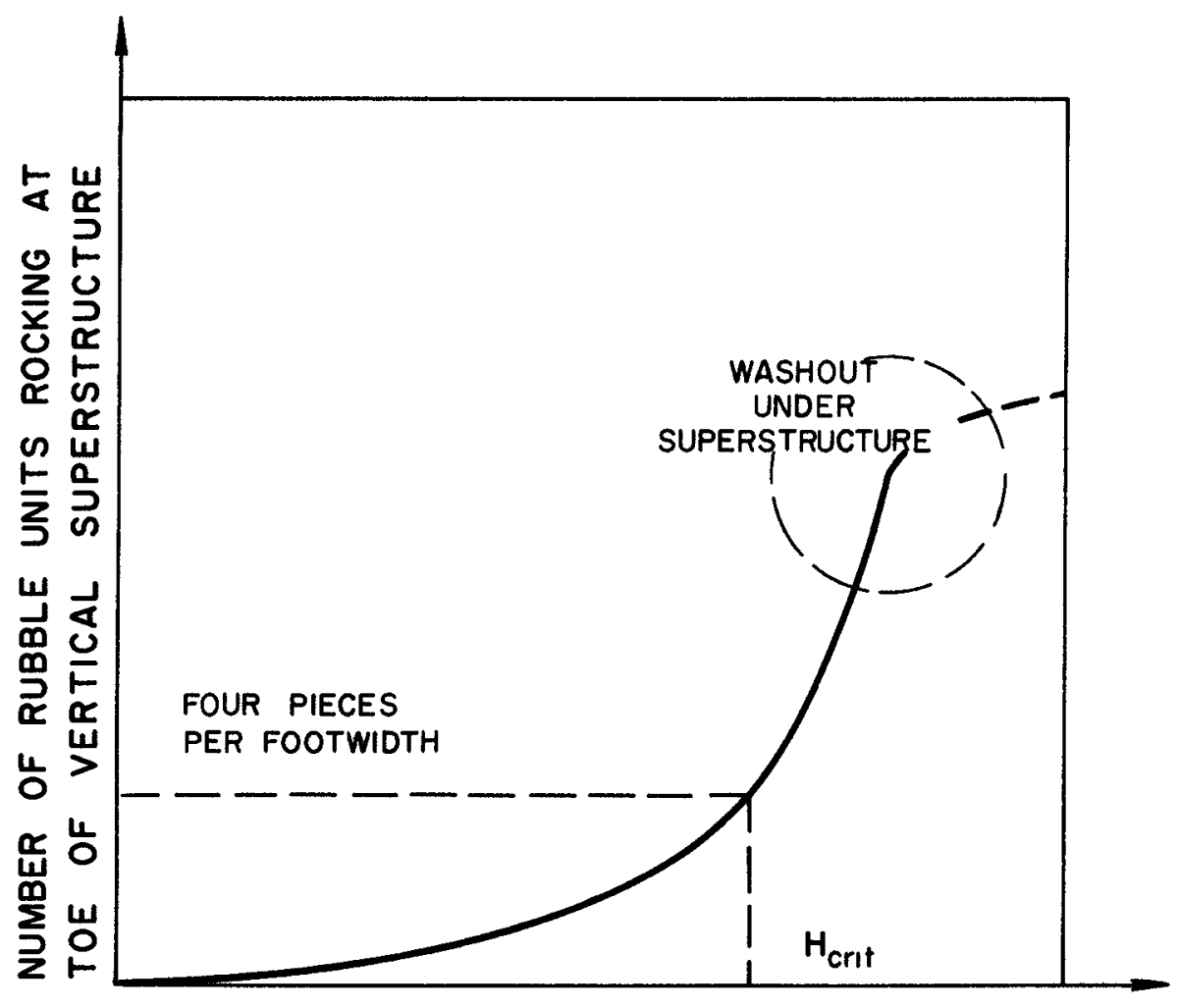

INCIDENT WAVE HEIGHT, H

Fig. 5

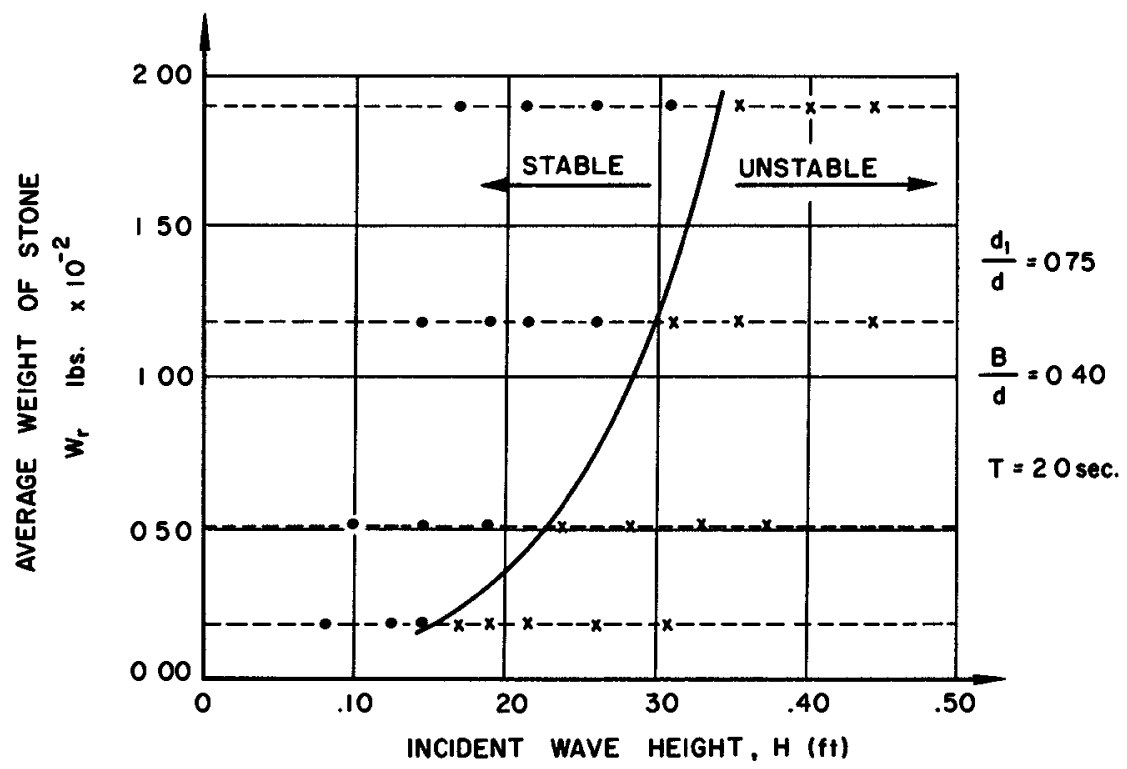

Fig. 6 


\section{LABORATORY STUDY OF RUBBLE FOUNDATIONS \\ FOR VERTICAL BREAKWATERS}
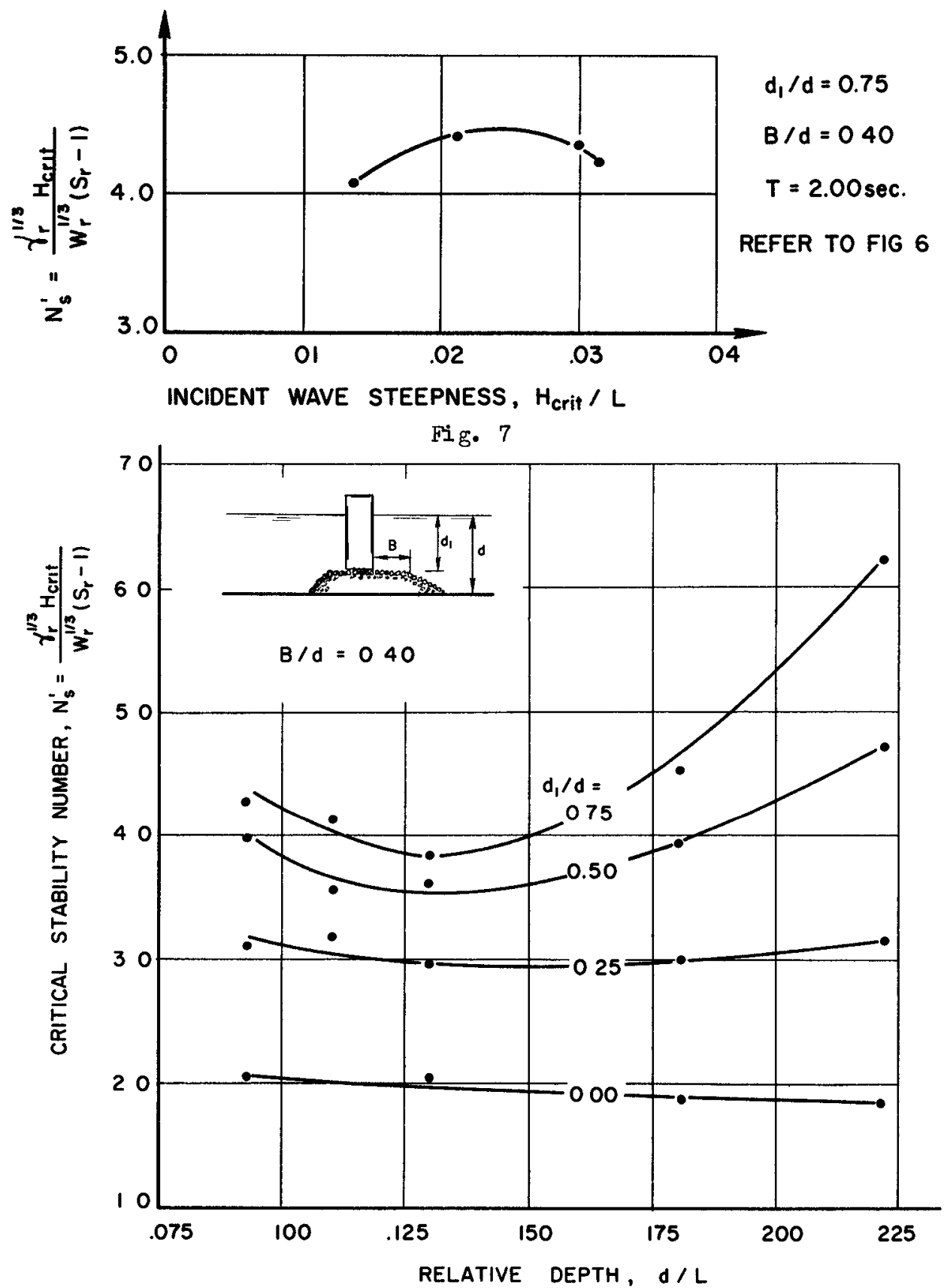

Fig. 8. Rubble mound as a foundation. Critical stability number, $\mathrm{N}_{\mathfrak{s}}$, as a function of relative depth, $\mathrm{d} / \mathrm{L}$. 


\section{COASTAL ENGINEERING}

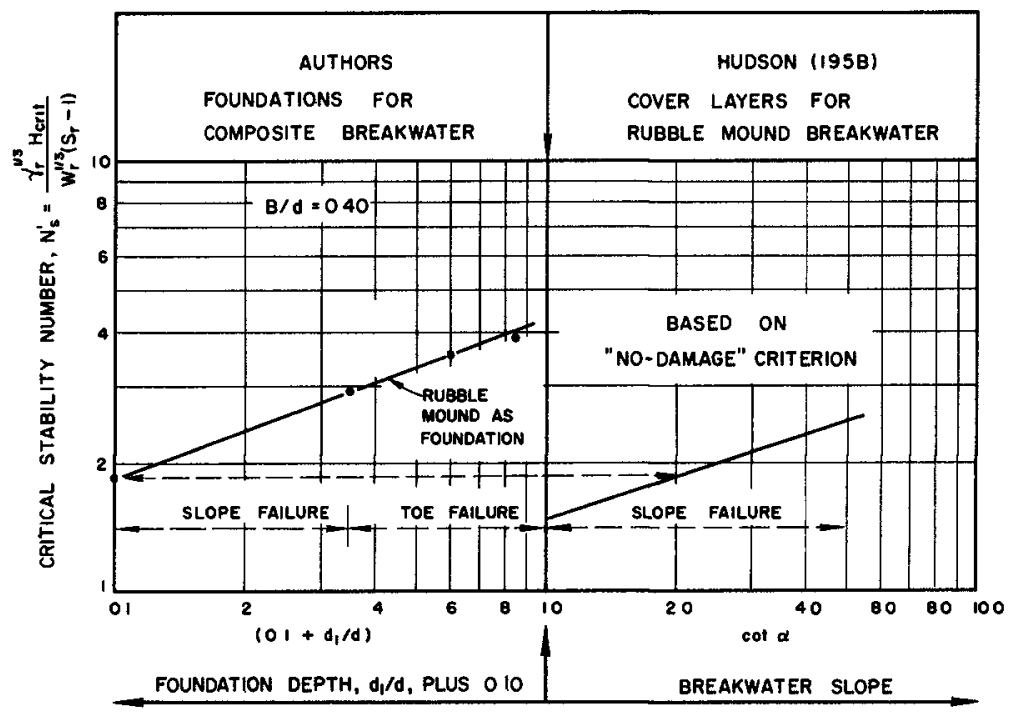

Fig. 9. Comparison of test results for composite breakwaters with results of Hudson (1958) for rubble mound breakwaters.

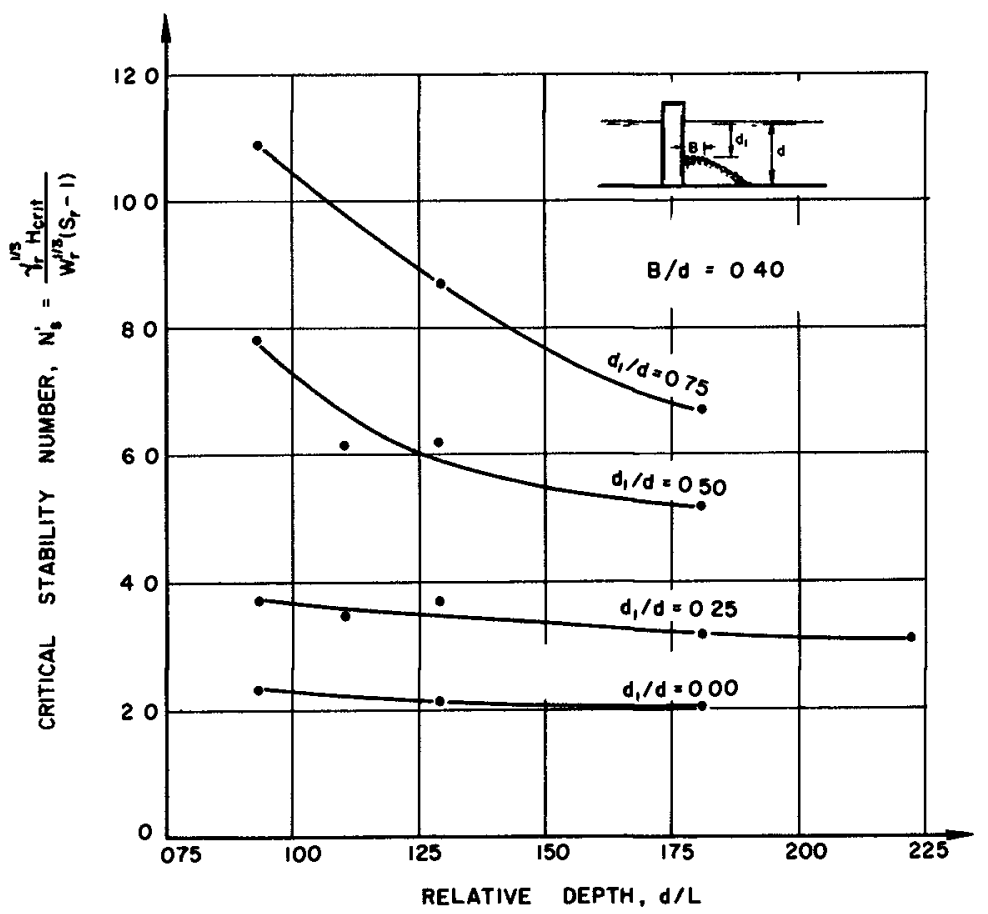

Fig. 10. Rubble mound as toe proteotion; critical stability number, $\mathrm{N}_{\mathrm{S}}$, as a funotion of relative depth, $d / L$. 


\section{LABORATORY STUDY OF RUBBLE FOUNDATIONS FOR VERTICAL BREAKWATERS}

Such a plot derived from Figure 8 is shown in Figure 9 along with Hudson's test results. (The comparison with the latter's results is permissible since Hudson used somewhat the same criterion of damage/ no damage or stable/ unstable conditions.)

\section{SUPPLEMENTARY TESTS}

Top Width of Mound:

In this series of tests the top width of the foundation mound,

$B$, on the seaward side was varied. (Reference may be made to Figure 3.) The additional widths tested were $B=0.15 \mathrm{~d}$ and

$B=0.75 \mathrm{~d}$. These tests were conducted only for the foundation depth $\quad d_{1} / d=0.50$ and $\quad d_{1} / d=0.75$.

It was found that variation in the top widths within the range stated above, did not result in significantly different Critıcal Stability Numbers from those already presented in Figure 8 for a foundation top width, $\quad B=0.4 \mathrm{~d}$.

Penetration of Superstructure in Mound:

To obtain an estimate of the effect of increasing the penetration of the superstructure into the mound foundation, the conditions illustrated in Figure 3(b) were tested. Here the superstructure extended to the floor of the wave tank and the rubble mound was piled in front to act as a toe protection. The results of these tests are depicted in Figure 10 where the variation of the Critical Stability Number, $N_{s}^{\prime}$, with $d / L$ and $d_{l} / d$ is shown.

\section{PRACTICAL APPLICATION OF RESULTS TO PROTOTYPE STRUCTURES}

Test results have, so far, been presented in terms of a Critical Stability Number, $N_{s}^{\prime}$, on the assumption that the structure was at the point of limiting equilibrium and that its ultimate safety was in some doubt. In the design of a structure, a definite margin of safety is required, and to arrive at a Design Stability Number, $N_{S}$, the Critıcal Stability Number, $N_{s}^{\prime}$, must be reduced. The reduction of the Critical Stability Number was achieved by re-examining the model test results and noting the wave height which caused no dama ${ }_{5}$ e to the foundation. This wave helght was denoted $H_{D}=0$ "No damage" was defined as follows:

a) When instability resulted from wash-out of the rubble from under the toe of the vertical superstructure (i.e. when $d_{1} / d>0.25$ and with little or no penetration of the superstructure into the rubble mound), "no damage" was taken as the condition where not more than two pieces per foot rocked slightly at the toe of the vertical superstructure. 
COASTAL ENGINEERING
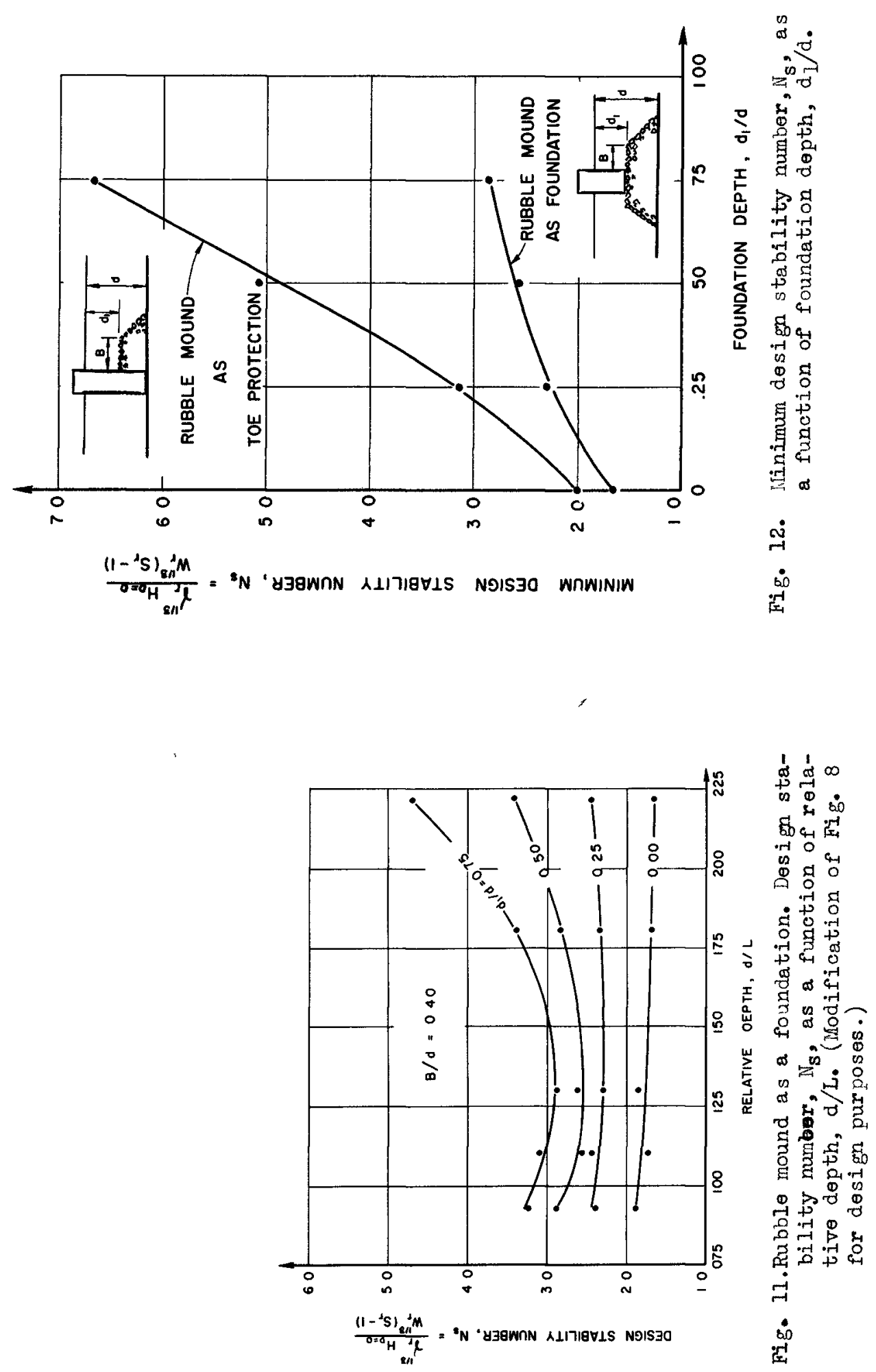


\section{LABORATORY STUDY OF RUBBLE FOUNDATIONS FOR VERTICAL BREAKWATERS}

b) When instability resulted from erosion of the seaward slope of the rubble mound (1.e. (1) when $d_{1} / d<0.25$ and with little or no penetration of the superstructure into the rubble mound, and (11) for all values of $d_{1} / d$ when the superstructure extended throu ig the mound to the floor.) "No damage" was taken as the condition where not more than $I$ per cent of the rubble units was displaced from the slope.

It must be emphasized that in effect there are two different stability criteria in use.

When $H_{D}=0$ was determined for all cases, the Critical Stability Number $N_{s}^{\prime}$, was reduced by multiplying it by the ratio

$$
\begin{aligned}
& \frac{H_{D=0}}{H_{\text {crit }}} . \\
& \text { Thus, Design } N_{s}=N_{s}^{\prime} \frac{H_{D=0}}{H_{C r i t}}
\end{aligned}
$$

In the test results for the case where the rubble mound was used primarily as a toe protection (Figu re 10$)$ it was not considered necessary to reduce the Stability Numbers for design purposes. $\left(\mathrm{H}_{\text {crit }}\right.$ for this case was taken as the height causing $1 \%$ of the outer layer of rubble units to be displaced - a permissible amount of damage in the field.)

Figure 11 shows the variation of the Design Stability Number, $N_{s}$, with $d / L$ and $d_{1} / d$, for zero penetration of the superstructure into the rubble mound.

Figure 12 is obtained from Figures 10 and 11 by noting the minimum values of $N_{s}$ for each value of $d_{l} / d$ and plotting this minimum $N_{s}$ as a function of $d_{1} / d$. Figure 12, then, presents the curves which are, at present, recommended for use in the design of rubble mound foundations and rubble mound toe protections for vertical breakwaters and seawalls.

Figure 12 has been used to calculate the curves shown in Figure 13 where the weight of rubble stone units required for given values of incident wave height, and selected values of specific weights of rock and water, may be obtained.

Design Wave Heights :

The proposed design curves of Figure 12 represent the relationship:

$$
\text { Design } N_{s}=\frac{f_{r}^{1 / 3} H_{D}=0}{w_{r}^{1 / 3}\left(S_{r}-1\right)}=f\left(d_{1} / d\right)
$$

The wave height in question is that which exists at the site of the structure and in the absence of the structure. 


\section{COASTAL ENGINEERING}

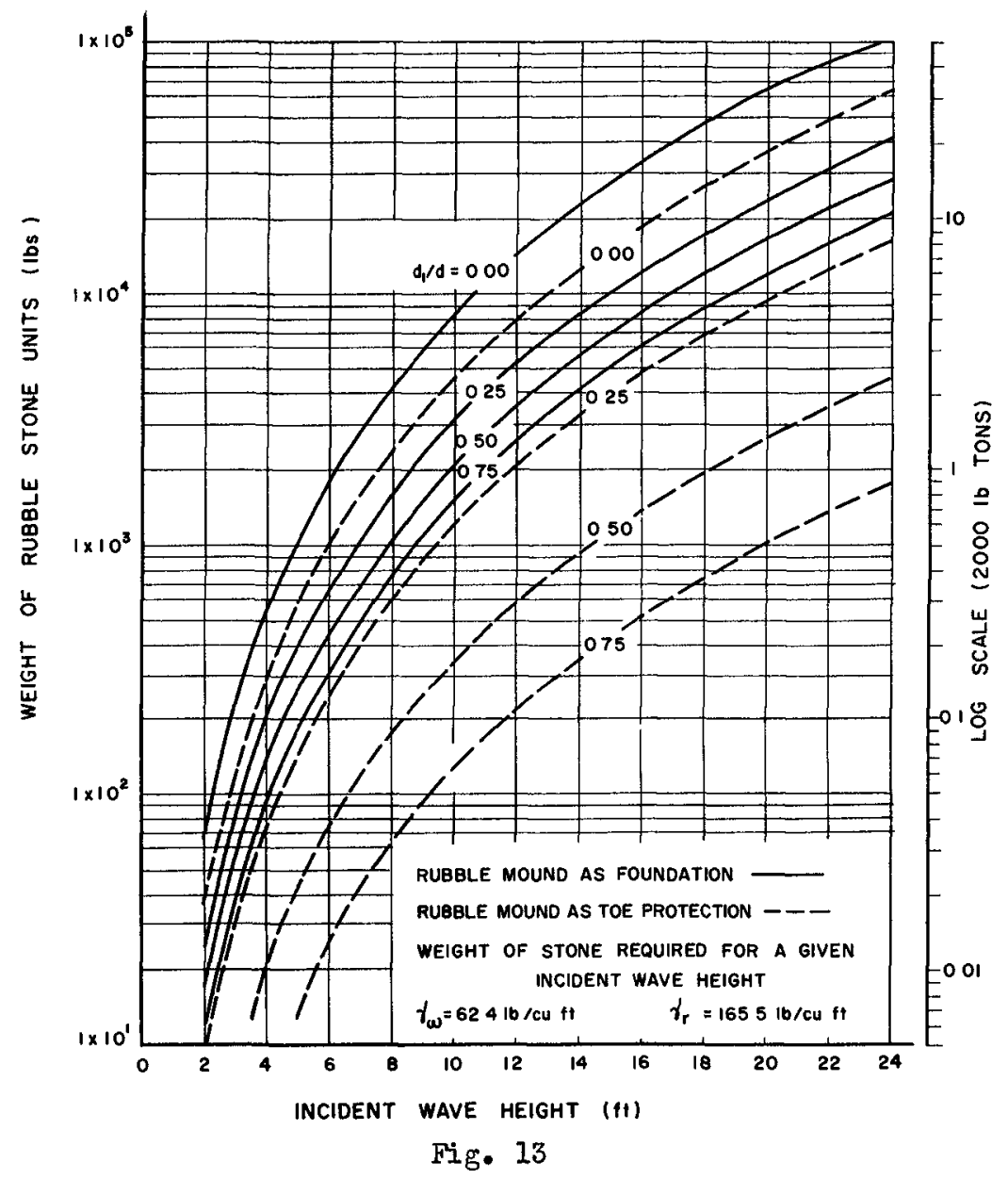

Most modern methods of wave forecasting give what has been termed the "significant wave", whose height is often denoted $H_{1 / 3}$. (The significant wave height, $H_{1 / 3}$, is defined as the average height of the highest one-third of waves.) Analysis of the statistical distribution of wave heights by Longuet-Higgins (1952) and Saville (1955) has shown that one wave in every hundred is likely to be 1.6 times the height of the significant wave, and that in a prolonged storm the maximum wave could be twice the height of the signuficant wave.

In the case of a composite breakwater with the superstructure resting directly on a rubble mound foundation, the safety of the whole structure and perhaps a whole harbour and the shipping in it, may depend on the ability of the foundation to resist the erosive effects of the highest waves. 


\section{LABORATORY STUDY OF RUBBLE FOUNDATIONS FOR VERTICAL BREAKWATERS}

Therefore, for use of the test results given herein, in the design of such structures, it is at present suggested that the design wave height, $H_{D}=0$, should be either

1. the maximum wave height measured at the vicinity of the site of the structure, if the duration of measurement is judged to be sufficiently long and accurate.

\section{OR}

2a. for important structures at very exposed sites where failure would be disastrous, and in the absence of factual records, the design wave height, $H_{D}=0$, should be twice the value of the expected wave height at the structure based on $H_{1 / 3}$ in deep water corrected for refraction and shoaling. (Breaking might preclude a wave of such magnitude and in such a case the greatest non-breaking wave should be taken for the design value of $H_{D}=0.1$

2b. for less important structures where some risk of exceeding design conditions is acceptable, one and a half times the expected wave height.

\section{DISCUSSION OF RESULTS}

In the present series of tests the rubble mound was composed entirely of stones of approximately uniform size. In practice, a rubble mound foundation would be constructed with a core of dumped blast-run rock or quarry waste. The superstructure might consist of concrete or timber cribs which would be founded on the core of blast-run rock. An alternative method of constructing the superstructure would be to drive a pair of parallel tied-together walls of steel sheet piling into the rubble core. Finally, the apron and side-slopes of the core would be protected from erosion, by a cover layer of heavier, more uniformly sized, rock.

It 1 s to the design of this cover layer that the tests described herein are intended to apply.

The practical prototype foundation is unlikely to correspond exactly to the conditions used in the present series of experiments. A situation where a superstructure, composed of steel sheet pile walls, is driven into the rubble core, corresponds most closely to the condition depicted in Figure 12 as "Rubble mound as toe protection". Other practical methods of construction are likely to fall somewhere between the two extreme conditions shown in Figure 12 .

The outstanding points of uncertainty are, therefore, the effects of varying degrees of impermeability in the layers composing a prototype foundation, and the effects of varying amounts of penetration of the vertical superstructure into the rubble mound. Increased penetration of the superstructure certainly increases the overall stability and safety, and a relatively impermeable core is anticipated to produce similar results. 


\section{COASTAL ENGINEERING}

In addition, the conditions at the pierhead, or seaward extremity of the structure, have not been investigated.

An analysis of prototype successes and failures in relation to the model test results would be invaluable in assessing the validity of the design curves proposed herein, and, if necessary, in their modification. Publication of data concerning such successes and failures would make this possible.

\section{CONCLUSIONS}

It is concluded from the results of model tests on the behaviour under wave action of a rubble mound foundation of a composite breakwater composed of rock of nearly uniform shape and size that:

a) the Stability Number, $\quad N_{s}=\frac{f_{r}^{1 / 3} H}{w_{r}^{1 / 3}\left(S_{r}-1\right)}$ is a useful and logical parameter for use in the study of the stability of rubble mounds under wave attack.

b) the Stability Number is primarily affected by the depth of the rubble mound foundation below the S.W.L. and by the relative depth $(d / L)$ at the breakwater site.

c) since waves in nature have widely differing wave-lengths it is advisable to design the foundation on the basis of the minımum value of design Stability Number appropriate to the particular foundation depth $\left(d_{1} / d\right)$.

d) increase in penetration of the superstructure into the rubble mound greatly increases the overall stability.

e) variation of the top width of the foundation mound on the seaward side, does not, for normal values of top width, appear to substantially affect the hydraulic aspects of the structure. In this respect, construction requirements and the dictates of Soil Mechanics will govern.

f) in the case of natural wave trains, the selection of the design wave height requires a decision on the part of the designer as to the acceptable risk of exceeding design conditions.

\section{ACKNOW LEDGEMENT}

The authors wish to acknowledge the contribution of the National Research Council of Canada and the Department of Public Works of Canada who made funds available for this study. 


\section{LABORATORY STUDY OF RUBBLE FOUNDATIONS FOR VERTICAL BREAKWATERS}

\section{RE FERENCES}

Beach Erosion Board, "Shore Protection, Planning and Design", Tech. Report No. 4, 1961 .

Beaudevin, C., "Stabilite des diques a talus a carapace en vrac", La Houlle Blanche - Mai-Juin, (1955).

Hudson, R.Y., "Laboratory Investigation of Rubble-mound Breakwaters", Proc. A.S.C.E., Waterways and Harbours Division, Vol. 85, No. WWS, Sept. 1959.

Iribarren, R., and Nogales, C., "Generalization of the Formula for Calculation of Rock-fill Dikes and Verification of its Coefficients", Translation No. 5I-4, Vickburg, Missippi, 1951.

Keulegan, G.H., and Carpenter, L.H., "Forces on Cylinders and Plates in an Oscillating Fluid", Journal of Research of Nat. Bur. of Standards, Vol. 60, No. 5, May 1958.

Minikin, R.R., "Winds, Waves, and Maritime Structures", Griffin and Company Ltd., London, 1950.

Naga1, S., "Shock Pressures Exerted by Breaking Waves on Breakwaters", Proc. A.S.C.E., Waterways and Harbours Division, Vol. 86, June 1960.

Saville, T. Jr., "Wave Forecasting", Proc, of 1st Conf. on Ships and Waves, Council on Wave Research, Richmond, Calif., 1955.

Longuet-Higgins, M.S., "On the Statistical Distr1bution of He1ghts of Sea-waves", Sears Foundation, J. Mar. Res., Vol. II, 1952 .

\section{APPENDIX - NOTATION}

\section{LIST OF SYMBOLS AS USED IN THIS PAPER}

Symbol

Definition

Units

B : Top width, on seaward side, of foundation mound. ft.

$C_{D} \quad:$ A drag coefficient.

$C_{M} \quad:$ An inertia coefficient.

d : Depth of Still Water measured from the bottom ft. normal to that Still Water surface; also, the depth of water in the vicinity of a structure. 


\section{COASTAL ENGINEERING}

$d_{1} \quad$ : Depth of top of foundation mound below the Still

ft. Water Level.

d/L : Relative Depth: ratio of still water depth of wave length.

D : A characteristic linear dimension of a rubble unit the diameter of a sphere having an equal volume.

- $D$ : A subscript referring to a drag force.

f : "a function of"

g: : Gravitational acceleration $\left(=32.2 \mathrm{ft} / \mathrm{sec}^{2}\right)$.

$\mathrm{ft} / \mathrm{sec}^{2}$

$\mathrm{H} \quad$ : Wave height; amplitude; height of incident wave. $\mathrm{ft}$

$H_{D}=0$ : Incident wave height causing "no-damage" to structure.

$H_{c r i t}$ : Critical wave height: Incident wave height at condition of limiting equilibrium of structure.

ft.

- : A subscript referring to the horizontal direction.

$H / L$ : Wave steepness: ratıo of wave height to wave length.

- I : A subscript referring to inertia force.

$k:=2 \pi / T$

$L \quad$ : Wave length.

ft.

$m \quad:=2 \pi / L$

$-_{\max }:$ A subscript referring to the maximum value.

$N_{s} \quad$ : A Stability Number for rubble mounds.

$$
N_{s}=\frac{\gamma_{r}^{1 / 3} H}{W_{r}^{1 / 3}\left(s_{r}-1\right)}
$$

$N_{s}^{\prime}$ : Critical Stability Number: Stability number at condition of limitıng equilıbrium -

$$
N_{s}^{\prime}=\frac{f_{r}^{1 / 3} H_{c r i t}}{w_{r}^{1 / 3}\left(s_{r}-1\right)}
$$




\section{LABORATORY STUDY OF' RUBBLE FOUNDATIONS ${ }^{-}$ \\ FOR VERTICAL BREAKW ATERS}

Sr : Specific Gravity of rubble or armour stone.

$\left(s_{r}=\gamma_{r} / \gamma_{f}\right)$

S.WL : Stıll Water Level.

$\uparrow \quad$ : A time.

secs.

T : Wave period.

secs.

u : Horizontal component of orbital velocity.

$\mathrm{ft} / \mathrm{sec}$

$v \quad$ : Vertical component of orbital velocity.

$\mathrm{ft} / \mathrm{sec}$

V : A velocity.

$\mathrm{ft} / \mathrm{sec}$

- $v$ : A subscript referring to the vertıcal direction.

$W_{r}$ : Weight of andividual unit of rubble mound foundation lbs. (actually the mean weight of a unit in a "nearly onesize" rubble mound.)

$x \quad$ : A horizontal distance from the origin of coordinates.

ft.

y : Depth below Still Water Level. (negative ft. downwards)

$\alpha \quad$ : Angle of a rubble mound (or breakwater) slope degrees measured from the horizontal.

$\beta \quad$ : A coefficient stating the proportionality of the weight of a rubble unit to its volume.

$\gamma_{f}$ : Unit weight of the water in which the structure is lbs/cu.ft. located.

$$
\begin{aligned}
& \boldsymbol{\gamma}_{r}=62.4 \mathrm{lbs} / \mathrm{cu} . \mathrm{ft} . \text { for fresh water } \\
& \boldsymbol{\gamma}_{\mathrm{f}}=64.0 \mathrm{lbs} / \mathrm{cu} . \mathrm{ft} \text {. for salt water. }
\end{aligned}
$$

$\gamma_{r}$ : Unit weight of rock (rubble).

$\mathrm{Lbs} / \mathrm{cu} \cdot \mathrm{ft}$.

$\Delta \quad$ : Denotes the shape of the rubble or armour units.

$\mu \quad:$ A friction coefficient.

$\left.\begin{array}{l}\sigma_{1} \\ \sigma_{2}\end{array}\right\}:$ Constants 